\title{
PROPAGANDA E REPRESENTAÇÃO: ANALISANDO DEFINIÇÕES CONCEITUAIS
}

\author{
Gustavo Feital Monteiro $^{1}$
}

Recebido em: 01/04/2020

Aprovado em: 05/10/2020

\begin{abstract}
Resumo: O presente artigo busca estudar a definição dos conceitos de representação e de propaganda, com o objetivo de delinear os limites de atuação de cada termo. Para essa atividade, serão observadas as análises de determinados autores cujos estudos demonstram as bases teóricas fundamentais de ambos, para posteriormente realizar a comparação dos significados individuais e apontar as suas aproximações ou divergências. Cada termo possui um grande espaço de debate com posicionamentos destoantes entre os acadêmicos, o que dificulta o estabelecimento de parâmetros estáveis de pesquisa. Ao contrapor as definições formadas por diferentes pesquisadores, procura-se esclarecer os pensamentos e as práticas apontadas na história que corresponderiam com um conceito ou com o outro, facilitando o exercício de sua identificação analítica juntamente com o aprofundamento da observação de seus efeitos na narrativa do passado. Assim, é o propósito desta análise identificar de qual forma os conceitos compartilham de características metodológicas na observação da sociedade, ressaltando a sua relevância para o exercício da pesquisa histórica e buscando incentivar uma abordagem mais aprofundada de ambos pela historiografia.
\end{abstract}

Palavras-chave: Propaganda; Representação; Teoria; Historiografia; História Cultural.

\section{PROPAGANDA Y REPRESENTACIÓN: ANALIZAR DEFINICIONES CONCEPTUALES}

Resumen: Este artículo busca estudiar la definición de los conceptos de representación y propaganda, con el fin de delinear los límites de actuación de cada término. Para esta actividad, se observarán los análisis de ciertos autores cuyos estudios demuestran las bases teóricas fundamentales de ambos, para luego realizar la comparación de los significados individuales y señalar sus aproximaciones o divergencias. Cada término tiene un amplio espacio de debate con posiciones diferenciadas entre los académicos, lo que dificulta el establecimiento de parámetros de investigación estables. En contraposición a las definiciones formadas por diferentes investigadores, buscamos esclarecer los pensamientos y prácticas señaladas en la historia que corresponderían con un concepto u otro, facilitando el ejercicio de su identificación analítica junto con la profundización de la observación de sus efectos en la narrativa del pasado. Así, el propósito de este análisis es identificar cómo los conceptos comparten características

\footnotetext{
1 Doutorando pelo PPGHIS da Universidade de Brasília. E-mail: gustaav.f@gmail.com. ORCID:
} https://orcid.org/0000-0003-2360-5515. 
metodológicas en la observación de la sociedad, resaltando su relevancia para el ejercicio de la investigación histórica y buscando incentivar un abordaje más profundo de ambos por la historiografía.

Palabras llave: Publicidad; Representación; Teoría; Historiografía; Historia cultural.

\title{
PROPAGANDA AND REPRESENTATION: ANALYZING CONCEPTUAL DEFINITIONS
}

\begin{abstract}
This article seeks to study the definition of the concepts of representation and advertising, in order to outline the limits of performance of each word. For this activity, the analyzes of certain authors will be observed, whose studies demonstrate the fundamental theoretical bases of both, to later carry out the comparison of the individual meanings and point out their approximations or divergences. Each term has a large space for debate with different positions among academics, which makes it difficult to establish stable research parameters. In contrast to the definitions formed by different researchers, this study seeks to clarify the thoughts and practices pointed out in history that would correspond with one concept or the other, facilitating the exercise of its analytical identification together with the deepening of the observation of its effects in the narrative of the past. Thus, the purpose of this analysis is to identify how the concepts share methodological characteristics in the observation of society, highlighting the relevance of both for the exercise of historical research and seeking to encourage a deeper approach to both by historiography.
\end{abstract}

Keywords: Propaganda; Representation; Theory; Historiography; Cultural History.

\section{Introdução}

O estabelecimento de bases teóricas e metodológicas para o estudo da sociedade reflete a complexidade do tema e a necessidade de diferentes fundamentos no desenvolvimento de perspectivas particulares. A representação e a propaganda são conceitos que, apesar de não serem facilmente compreensíveis em suas definições, se constituem como ferramentas analíticas para observar a sociedade no passado por diferentes maneiras. Ambos, no entanto, aparentam possuir elementos em comum, tanto em sua forma como no seu conteúdo, podendo causar dificuldades de delineação de seus limites específicos.

Enquanto que a representação é extensivamente estudada, como conceito e como prática, pela história cultural e possui uma reconhecida presença na historiografia, a propaganda não ocupa semelhante espaço de reflexão. Pelo contrário, o termo é quase desconhecido dos estudos culturais da sociedade, e o seu uso como abordagem metodológica de pesquisa, mesmo que existente desde a década de 1970, não é exercida por acadêmicos no Brasil.

Baczko, ao afirmar que a propaganda necessitava de maior estudo, refletia a pouca interdisciplinaridade entre a história e o campo social da propaganda política da época 
(BACZKO, 1985, 300). No entanto, numerosos trabalhos foram elaborados a partir do período das reflexões desse autor, contribuindo para a formação de uma melhor compreensão da relevância desse conceito e da sua utilização na abordagem do passado. Da mesma forma, outras reflexões sobre a história cultural e das representações desenvolveram esse campo, diversificando-o e aumentando o seu diálogo com outras disciplinas.

A propaganda, atualmente, se constitui em um campo amplo da história, cujo objeto de estudo é observado nas múltiplas formas de manifestação política, seja ela governamental ou não. Assim como a representação, a propaganda pode se expressar por meio de ideias, conceitos ou símbolos, mas também possui outros elementos que conferem maior complexidade ao seu significado. Dessa forma, a comparação de ambos os conceitos possibilita uma melhor compreensão de como podem abranger os mesmos elementos ao mesmo tempo em que se diferenciam em outros.

Ao aprofundar nos significados de cada termo, é possível apontar as principais características que os destacam de outros similares e que se constituem na centralidade de suas abrangências. As diferenças entre a propaganda e a representação são encontradas nos aspectos principais de suas definições, mas, ao mesmo tempo, isso não significa uma completa divisão entre ambos ou a ausência de influência de um sobre o outro no campo social. A multiplicidade de fatores no estudo da história não possibilita a construção de uma linearidade ou a elaboração de classificações monolíticas, fazendo com que cada conceito possua limites pouco definidos com outros termos, além de necessitar uma profunda reflexão em sua sustentação própria.

Partindo da análise individual, este estudo procura identificar quais seriam os seus limites como conceitos. Ou seja, o que pode ser considerado como parte de sua abrangência e quais os critérios para definir essas características nos objetos de estudo. Após tal atividade, é realizada a comparação entre ambos com o propósito de determinar até qual ponto podem compartilhar de definições similares e até qual medida eles podem ser considerados como campos distintos. Tal atividade pretende explorar melhor o conceito da propaganda e a sua relação com estudos da história cultural, assim como observar a conexão entre a sociedade com o discurso político de seu contexto no passado e no presente.

Com isso, busca-se esclarecer o incômodo apresentado por Baczko e aproximar mais a relação da história das representações com a propaganda, onde ambos possam servir para estudar a sociedade por meio de perspectivas individuais próprias e complementares. Como conceitos, tais termos se configuram como instrumentos metodológicos que contribuem para o melhor direcionamento da análise e maior possibilidade de compreensão da história, sendo, para isso, necessária a construção de uma definição melhor esclarecida de si. 


\section{Propaganda}

Apesar da sua extensa presença e relevância na política, a dificuldade de se definir o termo "propaganda" reflete a imprecisão de seus limites como fenômeno social. Usualmente considerada como enganosa ou manipuladora, a propaganda é associada com a imposição ideológica ou a disseminação de mentiras, o que interfere na análise de seu uso e na observação de seus efeitos sobre a sociedade em casos específicos. Ademais, a existência de tentativas de manipulação por meio de asserções falsas, sejam elas explícitas ou implícitas, não corresponde com a totalidade de sua prática, o que dificulta a atribuição de uma definição coerente a este termo. A princípio, portanto, é possível apontar ao menos dois obstáculos iniciais na atribuição de sentido para o conceito: a sua definição e a sua identificação na história. ${ }^{2}$

Para responder a esse duplo questionamento, no entanto, outros aspectos necessitam ser examinados. Considerando-a como um conjunto de práticas gerais ou como produtos específicos derivados do uso dos meios de comunicação, a propaganda é estudada juntamente com a sua capacidade de influência social. Não sendo um conjunto de manifestações isoladas, ela somente adquire sentido na medida em que é compreendida como parte de um contexto amplo, onde diferentes agentes e instituições atuam de diversas formas. A relação entre tais grupos sociais e políticos influencia o conteúdo e estabelece os formatos pelos quais a propaganda é elaborada e transmitida.

A inviabilidade de separação dos dois aspectos - o objeto e seus efeitos - contribui para ampliar a quantidade de elementos a serem considerados na sua abordagem analítica, tornando o tema ainda mais complexo e de difícil compreensão. Juntamente com esse aspecto, devem ser examinadas também as ideologias políticas contemporâneas, as práticas de representações sociais e as características da sociedade moderna a partir do século XIX, as quais conferem proporções mais amplas à configuração da propaganda através do relacionamento que possui com esses e outros elementos, tanto externos como inerentes.

\footnotetext{
${ }^{2}$ Ellul inicia o seu estudo ressaltando os equívocos iniciais do estudo de propaganda, defendendo a superação de tais preconcepções para a realização de uma observação objetiva: "Even when these obstacles have been removed, it is still very difficult to determine what constitutes propaganda in our world and what the nature of propaganda is." (ELLUL, 1973, x) Citação como no original.
} 
Os estudos iniciais da propaganda refletiram essa dificuldade de abordagem analítica. Ellul explora os argumentos apresentados por alguns estudiosos e ressalta a falta de consenso em uma definição específica (ELLUL, 1973, xii). No entanto, são destacados determinados princípios que direcionam a interpretação para a identificação de um aspecto em comum, essencialmente centrados no propósito da propaganda. Para o autor, após observar algumas de suas características, o principal aspecto se encontra nos objetivos e na intenção da propaganda:

Propaganda is a set of methods employed by an organized group that wants to bring about the active or passive participation in its actions of a mass of individuals, psychologically unified through psychological manipulations and incorporated in an organization. (ELLUL, 1973, 61)

Mesmo com a imprecisão de qualquer definição superficial estática devido à incapacidade de abrangência da variedade do seu uso na história, o propósito de persuadir comportamentos é considerado o principal aspecto da propaganda em suas variadas formas, assim como possibilita a sua diferenciação de outros termos análogos. Ou seja, os instrumentos de informação utilizados, a narrativa do discurso ou a estrutura social são elementos que não exercem influência para determinar o parâmetro da propaganda uma vez que são demasiadamente heterogêneos para compor uma delimitação pragmática.

Observando a variedade de práticas efetivas presentes na história, é possível identificar e diferenciar um conjunto coeso de políticas, valores e grupos sociais em relação entre si e com os meios de comunicação dos quais fazem uso para expressar seus ideais. Principalmente ao se considerar o século XX, é possível identificar diversos meios, instrumentos e ideologias presentes na propaganda política, tanto em níveis nacionais quanto em internacionais, os quais seriam derivados do crescente envolvimento social com a política contemporânea. Mesmo assim, a partir da percepção de seu aspecto principal, é possível identificar a prática da propaganda na história juntamente com as suas características e os objetivos daquele que a utiliza.

Ao estabelecer o princípio da intenção de disseminar ideias e influenciar comportamentos, a propaganda pode ser elaborada por meio de maneiras, formatos e conteúdos diversos ao mesmo tempo em que mantêm o seu principal fundamento. O significado da propaganda, dessa forma, é intrinsicamente ligado à sua presença no contexto social, onde emissor, mensagem e efeitos demonstram que a propaganda moderna se destina a aspectos psicológicos e, não restrita somente a eles, busca gerar a ação em indivíduos, como Ellul

\footnotetext{
${ }^{3}$ Citação como no original.
} 
destaca: "As long as no physical influence is exerted by an organization on the individual, there is no propaganda." (ELLUL, 1973, 20)

Outras análises contribuem para demonstrar as novas dimensões que a propaganda adquiriu nas últimas décadas. Acompanhando as inovações tecnológicas no campo das informações, a propaganda também se modificou, em formato e em discurso, para se adequar às mídias de massa em desenvolvimento nos séculos XX e XXI. Ao mesmo tempo, no entanto, algumas de suas características permanecem constantes e podem ser identificadas, em maior ou menor grau, em diferentes contextos e períodos. Esta definição é observada por Jowett e O’Donnell, os quais, apesar de críticos dos argumentos centrais de Ellul, ${ }^{4}$ também ressaltam que a propaganda é frequentemente elaborada de forma consciente e com um objetivo específico, procurando persuadir aqueles aos quais ela se dirige. ${ }^{5} \mathrm{O}$ trabalho dos autores reanalisa diversas das características abordadas por Ellul, contribuindo com a ampliação e o aprofundamento do estudo da propaganda através da abordagem das tecnologias recentes e por meio do fornecimento de exemplos dos acontecimentos da história ocorridos no período entre as publicações de ambos os livros. ${ }^{6}$

Os autores detalham a sua definição aprofundando nos termos "deliberado", "sistemático", "tentativa" e "atingir uma resposta", os quais demonstram a centralidade da sua argumentação (JOWETT; O'DONNELL, 2012, 7). Com essas características, a propaganda é interpretada a partir da intenção de seu emissor em influenciar determinado público; da forma metódica da aplicação dos instrumentos de comunicação para divulgar a mensagem; da tentativa de transmitir e ser internalizada e, por último, do propósito de gerar uma resposta, seja ela uma ação ou um modelo de pensamento. Dessa forma, a propaganda é observada como um processo de diferentes etapas que corresponde com objetivos políticos previamente

\footnotetext{
${ }^{4}$ Apesar de Ellul definir a propaganda como sendo elaborada por grupos específicos e correspondendo com interesses particulares, Jowett e O’Donnell afirmam que esse autor desconsidera as intenções dos emissores: "Although respectful of the work of Jacques Ellul, we could not incorporate many of his ideas within the text of the book. We aimed to clarify and distinguish propaganda as a form of communication but found that we could not do so with Ellul's view of the pervasiveness of propaganda." (JOWETT; O'DONNELL, 2012, xiv). Posterorimente complementando que: "He regarded propaganda as sociological phenomena, not as something made or produced by people of intentions. Ellul contended that nearly all biased messages in society were propagandistic even when the biases were unconscious." (JOWETT; O'DONNELL, 2012, 4)

5 "Our definition of propaganda focuses on the communication process - most specifically, on the purpose of the process: Propaganda is the deliberate, systematic attempt to shape perceptions, manipulate cognitions, and direct behavior to achieve a response that furthers the desired intent of the propagandist." (JOWETT; O'DONNELL, 2012, 7). Citação como no original.

${ }^{6}$ Mais de vinte anos separam a publicação do livro de Ellul em 1962 da obra de Jowett e O'Donnell em 1986, sendo que algumas modificações foram realizadas nas edições posteriores de Propaganda and Persuasion, havendo mais 25 anos entre a primeira edição e a quinta (JOWETT; O'DONNELL, 2012, xxv). Os autores ressaltam que estudos de caso foram acrescidos às novas edições de acordo com os acontecimentos históricos, assim como também foram incorporados ao texto novas bibliografias e a análise do uso de instrumentos modernos de propaganda, como a internet.
} 
considerados, ou, como os autores afirmam: "In our definition, the elements of deliberate intent and manipulation, along with a systematic plan to achieve a purpose that is advantageous to the propagandist, however, distinguish propaganda from a free and open exchange of ideas." (JOWETT; O'DONNELL, 2012, 17)

De forma mais centralizada, Welch inicia a sua abordagem partindo desse pressuposto e, assim como os autores anteriores, também delimita a propaganda a partir de seus efeitos intencionados. Ao considerar a propaganda como sendo predominantemente uma construção para gerar reações sociais que correspondessem com o interesse do emissor, o estudo de Welch se origina de casos onde houve uma elaboração eficaz de um governo para um fim específico: "The examples and case studies represent, in the main, propaganda campaigns that could be described as 'successful' in their historical contexts, from the point of view of the propagandist.” (WELCH, 2013, 190).

Ou seja, o autor procura destacar as características da propaganda política, com maior ênfase na sua atuação do século XIX em diante. Devido à sua perspectiva, ele aponta a Igreja Católica como a primeira instituição de propaganda, a qual teria os meios para disseminar um conjunto de ideias e a intenção de estabelecer uma doutrina que direcionaria o comportamento social. Mesmo com a sua capacidade de influência e o seu alcance limitados pelos recursos dos períodos anteriores à revolução industrial, a propaganda passou a ser considerada como conceito referente a práticas estabelecidas:

The first propagandist institute was therefore simply a body charged with improving the dissemination of a religious dogma. But the word 'propaganda' soon came to be applied to any organization set up for the purpose of spreading a doctrine. Subsequently it was applied to the doctrine itself, and lastly to the methods employed in undertaking its dissemination. (WELCH, 2013, 9)

Todos os autores citados estabelecem suas definições em termos semelhantes e, partindo de tais delimitações, consideram que o estudo da propaganda deve observar os seus efeitos sociais juntamente com a configuração de seu discurso. Seja ela bem ou malsucedida, a propaganda não é examinada como uma elaboração desconectada de seu ambiente social. Pelo contrário, ela corresponde com interesses específicos, é idealizada em formas previamente estudadas e faz uso de uma linguagem que procura estabelecer um meio de comunicação entre o emissor e o seu público para transmitir a sua mensagem.7 Paralelamente a tais aspectos, a

\footnotetext{
${ }^{7}$ Oriunda dessa análise, uma das características iniciais abordadas pelos autores é a relação da propaganda com a verdade. Assim como Ellul elabora, a propaganda deve possuir uma conexão com a verdade e com fatos para que possa ter credibilidade (ELLUL, 1973, 52). Neste sentido, Welch destaca que a propaganda não possui o poder de criar formas de pensamento ou comportamento que sejam distantes da realidade social, sendo mais eficaz quando corresponde com valores e ideias previamente existentes: "It is not, of course, an entirely new conclusion. Writing
} 
propaganda se estrutura em um método de divulgação centralizado e de fundamentação política, onde organizações, agentes ou grupos procuram divulgar suas ideologias através do uso dos instrumentos de informação de amplo alcance social.

No entanto, as obras mencionadas, mesmo abordando o mesmo tema, possuem algumas diferenças em sua perspectiva e metodologia de estudo. Inicialmente, é possível apontar as peculiaridades de cada a partir das perspectivas sobre as quais as argumentações são elaboradas. Ellul, escrevendo na França da década de 1950, focaliza a sua abordagem na descrição das características da propaganda e da sua presença no meio social, tanto como uma tentativa de manipulação ideológica como uma forma de estabelecimento de práticas sociais. 8 Jowett e O’Donnell também abordam as características da propaganda que auxiliam na sua definição e identificação, mas procuram explorar o processo de propaganda, desde a sua elaboração até a recepção, em diferentes períodos e contextos históricos. Welch, por sua vez, atribui uma relevância maior ao agente e às suas intenções como entidades políticas, não chegando a explorar as características internas da propaganda com detalhe semelhante ao estudo de Ellul ou de Jowett e O’Donnel:

More precisely, it can be defined as the deliberate attempt to influence the public opinions of an audience, through the transmission of ideas and values, for a specific persuasive purpose that has been consciously thought out and designed to serve the self-interest of the propagandist, either directly or indirectly. (WELCH, 2013, 2)

Outra diferença é derivada da identificação da propaganda na história. Uma vez que a definição estabelece a intenção de direcionamento das atitudes sociais e influência ideológica, é possível sustentar o argumento de que houve manifestações antes da idade moderna que poderiam ser classificadas como formas iniciais de propaganda política. A definição apresentada por Welch, assim como Jowett e O’Donnell, possibilita uma compreensão mais ampla da atividade de propaganda que passa a englobar desde o contexto da Grécia antiga até à idade contemporânea, levando em consideração as diferenças em método e forma: "The use of propaganda as a means of controlling information flow, managing public opinion, or manipulating behavior is as old as recorded history." (JOWETT; O'DONNELL, 2012, 52) ${ }^{9}$

in 1936, Aldous Huxley observed that 'the propagandist is a man that canalizes an already existing stream; in a land where there is no water, he digs in vain'." (WELCH, 2013, 28)

${ }^{8}$ É perceptível a influência que o contexto da Guerra Fria e a grande presença da propaganda internacional tiveram em seu pensamento como um todo, como o próprio autor menciona: "In the world today there are three great propaganda blocs: the U.S.S.R., China, and the United States. These are the most important propaganda systems in terms of scope, depth, and coherence. Incidentally, they represent three entirely different types and methods of propaganda." (ELLUL, 1973, ix)

9 Complementando posteriomente que: "The ancient world, prior to 500 b.c.e., provides many examples of effective propaganda techniques being used by rulers, mostly in support of war or religious persuasion." 
Ellul, por outro lado, defende que a propaganda pode ser considerada apenas a partir do uso da mídia de massa, sem a qual não haveria condições para a sua existência. Os meios modernos de comunicação não seriam somente usados como instrumento de disseminação, mas também teriam moldado a sociedade para criar a necessidade social da propaganda, a qual contribuiria para a compreensão da complexidade do mundo. $\mathrm{O}$ desenvolvimento social da idade contemporânea possibilitou a maior acessibilidade às informações e uma ampliação da influência dos acontecimentos anteriormente de relevância local ou nacional, fazendo com que a sociedade necessitasse de modelos interpretativos para entender o seu ambiente. Em outras palavras, a propaganda não estaria restrita a uma série de práticas coordenadas de influência ideológica, mas faria parte da estrutura social e contribuiria para atribuir um sentido ao contexto imediato. Segundo o autor:

Again I want to emphasize that the study of propaganda must be conducted within the context of the technological society. Propaganda is called upon to solve problems created by technology, to play on maladjustments, and to integrate the individual into a technological world. Propaganda is a good deal less the political weapon of a regime (it is that also) than the effect of a technological society that embraces the entire man and tends to be a completely integrated society. (ELLUL, 1973, xvii)

Para Ellul, apenas a partir das inovações tecnológicas, do desenvolvimento social e do envolvimento da população com assuntos políticos que a propaganda adquiriu maior presença no cenário cotidiano. Essa interpretação leva à terceira diferença encontrada nas obras, pois, enquanto os autores mais recentes focalizam os seus estudos na propaganda política, Ellul procura observá-la inserida em outras formas de comportamento social. A propaganda política mantém grande presença em seu estudo, mas o autor se dedica a ressaltar as divergências entre ela e a propaganda sociológica, a qual corresponderia com estruturas sociais que determinam comportamentos dos indivíduos a partir de valores e costumes compartilhados. ${ }^{10}$

(JOWETT; O'DONNELL, 2012, 53); e também, ao mencionar a Roma Antiga: “The Imperial Roman Empire, between 50 b.c.e. and c.e. 50, applied systematic propaganda techniques that used all available forms of communication and symbology to create an extremely effective and extensive network of control. The resulting "image" of Imperial Rome remains strong and has become an integral part of our popular culture, as we can all identify with the trappings associated with this great empire. Roman emperors developed their propaganda strategies to meet a very real need." (JOWETT; O'DONNELL, 2012, 56)

${ }^{10}$ A diferença entre propaganda política e a publicidade seria, segundo Ellul, mais facilmente identificável do que a propaganda sociológica. Um anúncio comercial, apesar de refletir valores presentes em seu contexto e poder ressaltar uma ideologia política na busca pelo seu público alvo, possuiria o objetivo principal voltado ao aspecto mercantil. $\mathrm{O}$ autor não nega o fato de os comerciais transmitirem, de maneira intencional ou inconsciente, uma mensagem política ou de reforçarem certas estruturas sociais juntamente com o produto, mas a centralidade da política e a intenção do anunciante são elementos centrais que distinguem ambos os conceitos. Ou seja, o propósito da publicidade seria expor e vender os produtos ou serviços, com a política e os costumes sociais transmitidos de maneira secundária em diferentes graus. O objetivo da publicidade não seria, dessa forma, a divulgação ideológica os dos valores aos quais faz referência, sendo que estas características estariam presentes como instrumentos ou reflexos da sociedade. Enquanto isso, a propaganda política possui o objetivo principal na ação política e na 
O ponto principal do estudo de Ellul se concentra na sua percepção da propaganda como parte integrante da sociedade contemporânea, contribuindo para fornecer sentido e explicação à complexidade do contexto imediato. Devido a essa interpretação, a propaganda política, mesmo sendo relevante, não corresponde isoladamente com a variedade de manifestações de propaganda existentes. De acordo com o autor, a propaganda sociológica define o conjunto de práticas e pensamentos que fariam parte da estrutura social, mas que não seriam determinadas por um agente específico ou direcionadas para objetivos previamente estabelecidos:

We call this phenomenon "sociological" propaganda, to show, first of all, that the entire group, consciously or not, expresses itself in this fashion; and to indicate, secondly, that its influence aims much more at an entire style of life than at opinions or even one particular course of behavior. (ELLUL, 1973, 62)

A propaganda sociológica denomina o processo difuso de transmissão de ideologias e modelos de comportamentos sociais, os quais podem incluir valores políticos. Por não haver centralidade na origem dessa forma de propaganda, ela é adaptada pelos grupos sociais que contribuem na sua manutenção e perpetuação. Ao invés de discursos explícitos de ideologia política, a propaganda sociológica estimula o comportamento inconsciente e hábitos naturalizados socialmente construídos nos indivíduos. Como o autor define: "Sociological propaganda is a phenomenon much more difficult to grasp than political propaganda, and is rarely discussed. Basically it is the penetration of an ideology by means of its sociological context." (ELLUL, 1973, 63) $)^{11}$

\section{Representação}

A propaganda sociológica de Ellul se assemelha, em sua definição, com a representação social observada pela história cultural, a qual, por sua vez, também possui seus próprios obstáculos para ser definida. Assim como a propaganda se relaciona com outros termos, a representação também é conectada com numerosos conceitos, como símbolo, significado e imaginário, junto aos quais necessita se fundamentar para construir seu sentido próprio. Como afirma Falcon:

As imprecisões terminológicas manifestam-se nas relações pouco claras que muitos textos estabelecem, ou permitem pressupor, entre as "representações sociais" e os "imaginários sociais" e, a seguir, entre estes e os mitos,

transmissão da ideologia fazendo com que a diferença entre os dois termos estaria presente no objetivo do emissor, mesmo que suas práticas sejam semelhantes e compartilhem dos meios de divulgação. (ELLUL, 1973, 62)

${ }^{11}$ Citação como no original. 
ideologias e utopias. O problema se complica mais ainda quando entram em consideração os respectivos conceitos, ora remetidos às representações em geral, ora aos imaginários. No caso da historiografia, porém, há dois novos complicadores a considerar: as noções de mentalidades coletivas e de memória social. Nesta mistura babélica de termos e conceitos, parece quase impossível estabelecer significações precisas, pois estas dependem da utilização que cada autor faz desta ou daquela noção. (FALCON, 2000, 49)

Cada conceito, dessa forma, é observado em meio a um conjunto de termos igualmente pouco delimitados com clareza em suas definições. Para evitar um prolongamento desnecessário na terminologia, é viável uma abordagem que se fundamente no significado de tais conceitos ao invés de se deter nas palavras em si. Ou seja, uma vez que o objeto de estudo é o conjunto de práticas sociais e os elementos que compõe os processos de atribuição de significados, o termo que denomina tais elementos não corresponde com as eventuais variações na medida em que se refere às mesmas práticas. Ao considerar o que tais palavras abrangem em seus significados, torna-se possível destacar em qual medida se assemelham e em quais pontos se distanciam.

Cada autor, no entanto, estabelece um conjunto próprio de conceitos sobre o seu objeto e os desenvolve por meio de perspectivas particulares de análise e argumentação. $\mathrm{O}$ que, a princípio, pode ser configurado como um exercício comparativo de definições explicativas, se desenvolve para a tentativa de estruturação paralela de diferentes modelos de estudo. Analisar o significado de representação acarreta na identificação de como o termo se enquadra dentro de interpretações singulares juntamente com outros conceitos de maior ou menor abrangência para, posteriormente, relacionar tais interpretações entre si no estabelecimento de níveis de significados e na delimitação de sua abrangência.

Partindo de tais observações, Baczko defende que o conjunto de símbolos socialmente construídos não são imagens sem função prática ou distantes do poder institucionalizado. Pelo contrário, tais elementos conferem legitimidade para os governos, fazendo parte da estrutura social e a relação da sociedade com a política. ${ }^{12}$ Em seu estudo, o "imaginário social" foi a denominação estabelecida ao processo de produção de representações que constituem a

\footnotetext{
${ }^{12}$ Ao destinar o início de suas reflexões para legitimar a pesquisa do imaginário social, o autor ressalta a conexão entre a imagem em torno da política, afirmando que: "Os bens simbólicos, que qualquer sociedade fabrica, nada tem de irrisório e não existem, efectivamente, em quantidade ilimitada. Alguns deles são particularmente raros e preciosos. A prova disso é que constituem o objecto de lutas e conflitos encarniçados e que qualquer poder impõe uma hierarquia entre eles, procurando monopolizar certas categorias de símbolos e controlar as outras. Os dispositivos de repressão que os poderes constituídos põem de pé, a fim de preservarem o lugar privilegiado que a si próprios se atribuem no campo simbólico, provam, se necessário fosse, o carácter decerto imaginário, mas de modo algum ilusório, dos bens assim protegidos, tais como os emblemas do poder, os monumentos erigidos em sua glória, o carisma do chefe, etc." (BACZKO, 1985, 299)
} 
percepção da realidade, atribuindo sentido e compondo a visão da sociedade sobre o seu contexto. Devido à essa função, o controle do imaginário acarreta um grande atributo político, capaz de direcionar a vida social a partir da influência sobre os seus símbolos no exercício do poder:

Os poderes que conseguem garantir o controlo, senão o monopólio, destes meios apropriam-se assim de uma arma tanto mais temível quanto mais sofisticada. É difícil sobrestimar as possibilidades que se abrem, deste modo, as iniciativas de tipo totalitário que visam anular os valores e modelos formadores diferentes daqueles que o Estado deseja, bem como condicionar e manipular as massas, bloqueando a produção e renovação espontâneas dos imaginários sociais. (BACZKO, 1985, 308)

Para o autor, a representação é um elemento dentro do imaginário social, o qual seria o objeto central de sua abordagem em uma perspectiva política. ${ }^{13} \mathrm{O}$ imaginário é apresentado como um modelo amplo de valores compartilhados, ou um sistema abrangente de signos e significados que atribuem sentido aos acontecimentos, no qual a representação exerce o papel de meio transmissor de uma ideia. Ela, por sua vez, seria uma construção simbólica com o objetivo de fazer referência ao imaginário, cuja função seria voltada à afirmação da identidade de um grupo social e a fundamentação de sua ideologia, além de influenciar o comportamento coletivo e de organizar estruturalmente a sociedade (BACZKO, 1985, 309). ${ }^{14}$

Diferente de Baczko, Hall considera outro conceito para definir os modelos explicativos sociais. Para o autor, a cultura compreende os significados compartilhados por determinada sociedade ou grupos, permitindo que diferentes indivíduos compreendessem o seu contexto de formas semelhantes (HALL, 2016, 19). A cultura seria compartilhada e seus valores compreendidos por meio de uma linguagem em comum, exercendo a função de sistema simbólico aos quais as ideias fariam referência. De acordo com essa perspectiva, ambos os elementos, linguagem e cultura, pertenceriam ao mesmo processo de compreensão do contexto como um todo, não somente de seus aspectos políticos. ${ }^{15}$

\footnotetext{
${ }^{13} \mathrm{O}$ autor considera o poder político como o principal elemento do imaginário social, como afirma em: "Com efeito, é no próprio centro do imaginário social que se encontra o problema do poder legítimo, ou melhor, para ser mais exacto, o problema da legitimação do poder. Qualquer sociedade precisa de imaginar e inventar a legitimidade que atribui ao poder." (BACZKO, 1985, 310)

${ }^{14}$ É relevante ressaltar o destaque o autor confere à construção das representações e o controle do imaginário como atividades intencionais na política, o que pode fortalecer a perspectiva da representação como próxima à da propaganda (BACZKO, 1985, 313). Contudo, mesmo reconhecendo a relevância do estudo dos dois campos para a compreensão do imaginário social, Baczko não explora uma definição própria para o conceito de propaganda, assim como não aprofunda sua análise nos trabalhos existentes sobre esse tema (BACZKO, 1985, 300).

${ }^{15}$ Hall destaca que uma cultura não é homogênea e seus significados não são compartilhados de forma igual por todos os grupos de uma mesma sociedade. A existência de diferentes culturas e de divisões internas em uma mesma cultura acarreta sistemas distintos de valores sociais e, consequentemente, de compreensão do contexto (HALL, 2016,20).
} 
Para Hall, a representação faria parte de um processo composto de diferentes elementos que, de forma interligada, fariam a conexão do contexto social com os modelos simbólicos culturais. Este processo não seria desenvolvido de forma linear ou unidirecional, com a linguagem exercendo a função de transmissor do sentido como um meio de representação: "Desse modo, a linguagem é uma prática significante. Qualquer sistema representacional que trabalhe nesses termos pode ser visto, de forma geral, como algo que funciona de acordo com os princípios da representação pela linguagem.” (HALL, 2016, 24)

Devido à aparente indeterminação dos conceitos e à falta de delimitação de seus aspectos, os autores buscaram a legitimação da representação como ferramenta heurística paralelamente com a sua definição. Dentre aqueles que abordam a história cultural, Chartier elabora a relevância do estudo das representações salientando que a estrutura social, os símbolos e os comportamentos coletivos são construções estabelecidas de acordo com os contextos, determinando as práticas e as relações entre diferentes grupos sociais na história. Para fundamentar a validade de sua abordagem, o autor responde diretamente algumas das principais críticas direcionadas a este tema, as quais estariam centralizadas nas características abstratas e imateriais das representações (CHARTIER 2012, 15). ${ }^{16}$

A história cultural, para o autor, se fundamenta no estudo do funcionamento social, o qual pode ser realizado por meio da observação de suas representações (CHARTIER, 1988, 16). ${ }^{17}$ Nessa perspectiva, a representação reflete a forma pela qual a sociedade se estrutura, se relaciona e estabelece imagens de si, fazendo com que a sua análise possibilite a percepção dos modelos que influenciam e determinam as configurações de seus grupos e conflitos internos. Após demonstrar o desenvolvimento da sua presença na historiografia, a representação é estabelecida dentro da percepção mais abrangente da história cultural:

\begin{abstract}
A definição de história cultural pode, nesse contexto, encontrar-se alterada. Por um lado, e precise pensá-la como a análise do trabalho de representação, isto é, das classificações e das exclusões que constituem, na sua diferença radical, as configurações sociais e conceptuais próprias de um tempo ou de um espaço. As estruturas do mundo social não são um dado objectivo, tal como o não são as categorias intelectuais e psicológicas: todas elas são historicamente produzidas pelas práticas articuladas (políticas, sociais, discursivas) que constroem as suas figuras. (CHARTIER, 1988, 27)
\end{abstract}

\footnotetext{
${ }^{16}$ A obra A história cultural (CHARTIER, 1988) foi elaborada, como afirmado pelo próprio autor, em resposta à "insatisfação sentida frente a história cultural francesa dos anos 60 e 70, entendida na sua dupla vertente de história das mentalidades e de história serial, quantitativa." (CHARTIER, 1988, 13)

${ }^{17}$ Chartier também ressalta a dimensão política das representações, sendo derivadas de interesses e objetivos específicos mais visíveis quando em conflito por espaços sociais: "As representações do mundo social assim construídas, embora aspirem a universalidade de um diagnostico fundado na razão, são sempre determinadas pelos interesses de grupo que as forjam. Daí, para cada caso, o necessário relacionamento dos discursos proferidos com a posição de quem os utiliza." (CHARTIER, 1988, 17)
} 
O principal elemento em questão seria, neste debate, a possibilidade de abrangência do real ou verdadeiro pela história e quais seriam as formas de realizar tal estudo. Levada a um extremo interpretativo na pós-modernidade, houve a ampliação do alcance das representações, chegando a englobar a própria pesquisa histórica. Considerando os estudos históricos como construções linguísticas ou narrativas, o "verdadeiro" seria inacessível nesta perspectiva e, portanto, não seria possível considerar tais estudos com maior ou menor validade, pois seriam todos igualmente distantes da "realidade do passado" (FALCON, 2000, 60). Mesmo que tais críticas tenham sido respondidas ou superadas de diferentes formas, permanece a questão da acessibilidade e da validade da história ao observar e interpretar os acontecimentos por meio de suas representações, as quais seriam subjetivas e inconsistentes.

As interpretações defendidas por Chartier e pelos outros autores demonstram que essa pergunta é falha em sua formulação. A representação não seria um meio de acesso à realidade uma vez que ela consiste como parte da estrutura social, compondo o contexto como fator relevante de práticas, comportamentos e mentalidades. Em outras palavras, a representação faria parte da realidade social e exerceria influência não apenas em ações coletivas, mas também na organização política, sendo mais do que construções ou reflexos imagéticos sem essência. Como define Chartier:

Assim construído, o conceito de representação foi e é um precioso apoio para que se pudessem assinalar e articular, sem dúvida, melhor do que nos permitia a noção de mentalidade, as diversas relações que os indivíduos ou os grupos mantem com o mundo social: em primeiro lugar, as operações de classificação e hierarquização que produzem as configurações múltiplas mediante as quais se percebe e representa a realidade; em seguida, as práticas e os signos que visam a fazer reconhecer uma identidade social, a exibir uma maneira própria de ser no mundo, a significar simbolicamente um status, uma categoria social, um poder; por último, as formas institucionalizadas pelas quais uns "representantes" (indivíduos singulares ou instancias coletivas) encarnam de maneira visível, "presenteiam" a coerência de uma comunidade, a força de uma identidade ou a permanência de um poder. (CHARTIER, 2012, 20)

Levando essas reflexões em consideração, é possível afirmar que a história cultural, e em especial o estudo de representações, não tem apresentado um diálogo com a propaganda em suas abordagens mais frequentes, mesmo após o desenvolvimento desse campo de estudo e a sua interdisciplinaridade com outras metodologias. Como Rubin aponta, a pesquisa da cultura pela história demonstrou uma grande ampliação nas últimas décadas, passando a envolver a linguagem, a antropologia e diversas outras formas de análise em suas observações (RUBIN, 2002). Ao mesmo tempo, incorporou também elementos empíricos anteriormente 
desconsiderados, contribuindo para a maior diversidade na fundamentação de suas interpretações:

The 'cultural turn' is served by a hybrid of critical strategies which illuminate modes of communication, the circulation of ideas and practices and the agency of the individual, and which always attend to meaning. It is best when practised with an awareness of the intellectual roots of its concepts and procedures, alert to the allure of its rhetoric. To deal with culture is thus to deal by definition with the mixing of categories, for it is the system of meanings which makes order, ranks priority and suggests useful connections between things - real, felt and imagined. (RUBIN, 2002, 90).

Ainda assim, não se chegou a considerar a propaganda como parte desses elementos, mesmo havendo grandes semelhanças entre suas características. A especificidade da propaganda como uma expressão de interesses políticos poderia, a princípio, destinar a sua classificação de forma mais apropriada como pertencente à história política. Isso permitiria o seu desenvolvimento dentro do estudo do discurso político e da relação entre a ideologia com a sociedade na qual está inserido.

Porém, essa percepção também é excludente da relação que a propaganda tem com a cultura e, principalmente, com as representações políticas. Ao invés de distanciar e delimitar tais conceitos em campos analíticos distintos, torna-se mais construtivo observar as suas semelhanças e identificar quais são os fundamentos metodológicos que ambos os termos compartilham. Dessa forma, os estudos da cultura e da propaganda podem contribuir para a melhor percepção dos discursos sociais e da relação deles com a política no passado.

\section{A propaganda e a representação seriam equivalentes?}

Comparando as definições dos conceitos, a propaganda se constitui de práticas mais delimitadas, o que indicaria uma maior facilidade de sua identificação e estudo na história. Por outro lado, a representação é associada com a cultura ou o imaginário social, os quais seriam termos de ampla abrangência, mas que correspondem com valores sociais, modelos de comportamentos e outros campos presentes no contexto que demonstram um objeto maior e mais profundo de estudo. Devido à sua pouca especificidade, as representações e os sistemas sociais podem se referir a uma quantidade de elementos superior em número e em complexidade do que a propaganda política.

Enquanto Baczko utiliza o termo "imaginário", Hall considera a "cultura" e Chartier aprofunda na "representação", estes autores se voltam para o mesmo objeto de pesquisa, 
descrevendo-o em termos semelhantes. Os elementos que compõe esse tema são essencialmente os modelos compartilhados de significados e os processos pelos quais esses signos são transmitidos na sociedade, formando as estruturas e as identidades de cada contexto. Independentemente de sua denominação, o ponto principal a ser considerado é como a representação contribui no estabelecimento e na manutenção de mentalidades socialmente compartilhadas e direcionam os comportamentos de grupos por meio de seu poder simbólico.

Assim como propaganda, a representação pode se referir a processos amplos de transmissões de significados e pode denominar elementos específicos dentro deste processo. Ambos são considerados como pertencentes às práticas sociais e fazem parte de sistemas mais amplos de poder político ou de construção de identidades culturais. Os demais termos associados também possuem definições aproximadas ao ponto de convergirem em espaços semânticos similares, interferindo na sua diferenciação individual e na sua identificação em casos específicos.

Por outro lado, mesmo sendo mais delimitada, a propaganda se configura em diferentes formatos e, devido a essa variedade, a sua observação crítica também deve salientar cada particularidade constituinte da sua expressão. Cartazes, panfletos, jornais, discursos, manifestações e filmes podem ser inseridos em uma denominação ampla de política, mas cada um desses meios também pode ser considerado como instrumento de representação. A convergência entre determinados objetos dos dois campos de estudo reflete as similaridades e os espaços onde as distinções entre ambos podem parecer turvas. Uma vez que a representação e a propaganda política podem se referir às mesmas práticas, torna-se válido questionar o que pode ser considerado como político nas representações. ${ }^{18}$

A pergunta que se apresenta na comparação entre estes dois termos é em qual medida a propaganda e a representação compartilham de sentidos similares e em quais pontos eles se diferem. Se ambos definem práticas e características sociais em comum, seria possível estabelecer delimitações precisas que determinassem a sua aplicabilidade interpretativa?

O principal elemento de diferenciação é identificado na característica política da propaganda. Como sustentado pelas análises citadas, a propaganda é necessariamente derivada de interesses políticos e possui ideologias específicas nos centros de suas mensagens, com

\footnotetext{
${ }^{18}$ Perspectivas abrangentes podem desenvolver essas questões de maneira demasiadamente abstrata, podendo chegar a conclusões onde todos os elementos sociais possuem fundamentação política. Mesmo levando em consideração um princípio de validade a essa argumentação, dificilmente os diferentes elementos culturais existentes em determinado contexto social possuem influência, espaço ou objetivos políticos em uma mesma medida. Ao se comparar grupos sociais ou governos distintos, percebe-se que a propaganda política e as representações são heterogêneas não somente em formato e em conteúdo, mas também em gradação.
} 
objetivos e métodos de disseminação planejados. As representações, por outro lado, não se restringem somente a valores ideológicos, assim como não são exclusivamente concebidas de forma prévia para realizar funções claramente estabelecidas. Como parte de modelos culturais ou de imaginários sociais, elas abrangem outros aspectos sociais além das ideologias políticas e possuem um desenvolvimento descentralizado na sociedade.

Porém, essa primeira interpretação gera outro questionamento: o que pode ser classificado como político nas representações? Ao invés de apresentar uma interpretação abrangente que ignore as particularidades de contextos específicos, a resposta à divisão entre política e cultura em uma sociedade é mais bem estudada em cada caso determinado. Uma vez que diferentes sociedades consideram aspectos singulares para estabelecer as linhas divisórias entre a política, religião ou a cultura, dificilmente é viável a formação e a defesa de uma concepção igualmente válida para todos os contextos. Da mesma forma, grupos menores também se posicionam de formas individuais com relação a esses temas, havendo variados graus de influência em suas concepções e identidades. ${ }^{19}$

Observando por outra perspectiva, essa questão também pode ser apresentada a partir da influência da política como um elemento social: o que pode ser classificado como cultural na política? Ou seja, de quais formas os governos se utilizam ou fazem referência a valores culturais para fundamentar suas ideologias? Ao considerar esse questionamento, é possível observar como a diferenciação entre cultura, política e religião não são claramente estabelecidas, mesmo na idade contemporânea. $\mathrm{O}$ estudo das representações e da propaganda permite analisar como, em uma mesma narrativa, diferentes elementos sociais podem ser identificados em variados níveis, alguns de forma mais implícita do que outros.

Por exemplo, esse debate não possui validade para o estudo de regimes totalitários, uma vez que não existem espaços sociais que não sejam classificados de políticos pelo governo. A distância entre os valores políticos e as práticas culturalmente estabelecidas se torna irrelevante uma vez que se buscava inserir todos os aspectos da vida social dentro da sua esfera de influência ideológica. Uma das características que distingue o totalitarismo de outros modelos de governo ditatorial é a ausência de diferenciação entre os espaços sociais, fazendo com que não houvesse diferença entre público e privado ou entre cultura e política. ${ }^{20}$

19 Por exemplo, podem-se mencionar grupos religiosos que possuem forte conexão com sua fé e cultura tradicionais, influenciando-os de maneira mais ativa a sua mentalidade e comportamentos em sociedade.

${ }^{20}$ Com relação ao nazismo, Mosse afirma: "This society would not allow for the differentiation between politics and daily life which many of us naturally make. Today, in most of the non-Communist Western world, politics is regarded as merely one compartment of life; it does not have to penetrate our very thought and being. But Hitler's aim was to construct an organic society in which every aspect of life would be integrated with its basic purpose. 
Portanto, é possível afirmar que a propaganda e a representação possuem semelhanças em seus formatos, mas se constituem de práticas sociais diferentes pelo seu conteúdo e função. Em poucas palavras, a propaganda é voltada para a política, enquanto a representação se estabelece como predominantemente social. Tais características podem se mesclar em certos contextos e situações de acordo com o envolvimento cultural da sociedade na política ou da politização da cultura em uma sociedade, mas a presença da ideologia política como elemento central da propaganda permanece sendo um fator de diferenciação da representação, a qual é mais extensa na sua abrangência.

Essa definição, no entanto, não possui uma capacidade de delimitação definitiva. Por mais que algumas circunstâncias demonstrem uma fácil identificação, não é uma atividade simples apontar o que se constitui como um elemento político em uma sociedade. Festivais, música, pintura ou outras manifestações culturais apresentam, em maior ou menor escala, questões políticas. Da mesma forma, uma propaganda pode não expressar explicitamente a sua ideologia política, sendo comum a sua disseminação juntamente com outros meios discursivos.

É nessa convergência indefinida que os estudos da propaganda e da representação possuem maior validade e melhor aplicabilidade. Uma vez que ambos correspondem em práticas sociais que coexistem, a sua abordagem conjunta possibilita a observação de características que poderiam não ser percebidas através de uma forma apenas. Assim como o político penetra e compõe a estrutura social juntamente com as práticas representativas, o estudo da propaganda permite a abordagem de um contexto social em conjunto com as suas representações.

Em certa medida, a propaganda pode ser classificada como uma forma de representação. No entanto, as suas características próprias e seu desenvolvimento distinto das demais representações sociais a configuram como uma prática que, apesar de suas proximidades, é mais bem estudada em seu próprio campo analítico. Isso não significa que esse conceito deve ser desconsiderado na abordagem da história cultural. De maneira oposta, o reconhecimento de um campo de estudos próprio para a propaganda possibilita a abordagem dessas questões por métodos mais específicos.

A propaganda se constitui em um conceito de extensa bibliografia e ampla aplicação metodológica. Com o crescente envolvimento social com assuntos políticos nas últimas décadas, o estudo das representações por meio da história cultural abrange, inevitavelmente, a relação entre a política, a ideologia e a linguagem que os conecta. A propaganda é uma prática

And in the terms in which this purpose was promulgated by the National Socialist party, no one could be allowed to stand aside." (MOSSE, 2003, xx) 
não apenas existente, mas intensivamente presente e extensivamente praticada na época contemporânea. Para abordá-la de maneira analítica apropriada, é necessário, essencialmente, o reconhecimento da sua relevância como conceito e a utilização de uma perspectiva própria de observação, a qual destaque a sua centralidade na prática do discurso político.

\section{Referências bibliográficas}

BACZKO, Bronislaw. A imaginação social. In: Enciclopédia Einaudi, vol. 5. Lisboa: Imprensa Nacional - Casa da Moeda, 1985.

CHARTIER, Roger. A história cultural: entre práticas e representações. Lisboa: Difel, 1988.

fev. 2012.

. Defesa e ilustração da noção de representação. Fronteiras, v. 13, n. 24, p. 15-29,

ELLUL, Jacques. Propaganda: the formation of men's attitudes. Vintage, 1973.

FALCON, Francisco J. Calazans. História e representação. In CARDOSO, Ciro Flamarion; MALERBA, Jurandir. Representações: contribuição a um debate transdisciplinar. Campinas, SP: Papirus, 2000.

HALL, Stuart. Cultura e Representação. Rio de Janeiro: Ed. PUC-Rio: Apicuri, 2016.

JOWETT, Garth S.; O'DONNELL, Victoria. Propaganda and persuasion. 5th ed. California: SAGE Publications, 2012.

MOSSE, George L. Nazi Culture: Intellectual, Cultural, and Social Life in the Third Reich. University of Wisconsin Press, 2003

RUBIN, Miri. What is Cultural History Now? in: CANNADINE, David (Ed.). What is History - Now?. Basingstoke: Palgrave Macmillan, 2002.

WELCH, David. Propaganda: power and persuasion. The British Library, 2013. 